\title{
Compressive Behaviour of Circular, Square, and Rectangular Concrete-Filled Steel Tube Stub Columns
}

\author{
Alireza Bahrami ${ }^{1,2, *}$, Ali Mahmoudi Kouhi \\ ${ }^{1}$ Department of Building Engineering, Energy Systems, and Sustainability Science, Faculty of Engineering and Sustainable \\ Development, University of Gävle, 80176 Gävle, Sweden \\ ${ }^{2}$ Department of Civil Engineering, Abadan Branch, Islamic Azad University, Abadan, Iran
}

Received August 24, 2020; Revised October 22, 2020; Accepted October 30, 2020

\section{Cite This Paper in the following Citation Styles}

(a): [1] Alireza Bahrami, Ali Mahmoudi Kouhi, "Compressive Behaviour of Circular, Square, and Rectangular Concrete-Filled Steel Tube Stub Columns, "Civil Engineering and Architecture, Vol. 8, No. 5, pp. 1119-1126, 2020. DOI: 10.13189/cea.2020.080538.

(b): Alireza Bahrami, Ali Mahmoudi Kouhi (2020). Compressive Behaviour of Circular, Square, and Rectangular Concrete-Filled Steel Tube Stub Columns. Civil Engineering and Architecture, 8(5), 1119-1126. DOI: 10.13189/cea.2020.080538.

Copyright $\bigcirc 2020$ by authors, all rights reserved. Authors agree that this article remains permanently open access under the terms of the Creative Commons Attribution License 4.0 International License

\begin{abstract}
In this paper, the compressive behaviour of circular, square, and rectangular concrete-filled steel tube stub (CFSTS) columns is assessed. Nonlinear three -dimensional finite element models for simulating the behaviour of the columns are developed with the aid of the finite element analysis package ABAQUS. Modelling result is compared with the experimental test result to validate the modelling. It is found that the obtained load-axial strain curves of the columns from the finite element analysis and experimental test are notably close to each other and the modelling is finally validated. Then, the analyses of the developed models of the columns are done in accordance with the validated method. Various parameters are adopted in the analyses including the load eccentricity, cross-sectional shape, and steel tube thickness. It is concluded that as the load eccentricity of the columns is increased, their ultimate load-carrying capacity, energy absorption capacity, and stiffness are decreased. Also, the circular columns have generally better performance than their rectangular and square counterparts. The hierarchy of the cross-sectional shapes of the columns from the ultimate load-carrying capacity and energy absorption capacity viewpoints is the circular, rectangular, and square shapes. Although the initial stiffness and slope of the stiffness curves of the rectangular and square columns are slightly higher than those of the circular columns, their stiffness distribution is non-uniform. Furthermore, thicker steel tube leads to greater ultimate load-carrying capacity, energy absorption capacity, and stiffness. Failure modes of the
\end{abstract}

columns are achieved and discussed as well.

Keywords Concrete, Steel, Tube, Stub Column, Energy Absorption Capacity, Stiffness, Load-Carrying Capacity

\section{Introduction}

Concrete-filled steel tube (CFST) columns are made up of steel tube and concrete infill. In the fabrication of the CFST columns, concrete is poured in layers inside the steel tube and vibrated by a vibrator. The advantages of large ductility of steel and high stiffness of concrete have appropriately been combined by the CFST columns. The CFST columns have increasingly been used in civil engineering structures throughout the world. Economies of reinforced concrete columns and the speed of construction and the constructability of steel columns have been provided by the CFST columns. These accomplished advantageous points by the CFST columns have resulted in significant economic saving in the overall structures of projects.

Several research works can be found in the literature on the CFST columns. The use of high strength concrete in steel box columns was examined by Uy and Patil [1]. Liu et al. [2] performed tests of high strength rectangular concrete-filled steel hollow section stub columns with 
different aspect ratios subjected to axial loading. Self-consolidating concrete-filled hollow structural steel stub columns were tested by Han et al. [3]. Tao et al. [4] conducted tests of concrete-filled stiffened thin-walled steel tubular columns. Han et al. [5] evaluated concrete-filled steel tubular stub columns subjected to axially local compression. Liew and Xiong [6] reported the effect of preload on the axial capacity of concrete-filled composite columns. Passive confinement effect of the steel tube in concrete-filled steel tubular columns was studied by Oliveira et al. [7]. Performance of concrete-filled stainless steel tubular columns was assessed by $\mathrm{Uy}$ et al. [8] under axial compression and combined action of axial force and bending moment. Bahrami et al. [9-11] investigated and developed unstiffened and stiffened concrete-filled steel composite stub columns. An experimental study of concrete-filled round-ended steel tubular stub columns was done by Faxing et al. [12] under axial compression. Zhu et al. [13] did experimental and numerical studies of large diameter concrete-filled high strength steel tubular stub columns subjected to axial compression. Behaviour of concrete-filled cold-formed steel tubular stub columns with thicker tubes was experimentally examined by Zhu et al. [14]. Li et al. [15] described mechanical behaviour of eccentrically loaded high strength concrete-filled high strength square steel tube stub columns. Jin et al. [16] presented a three-dimensional meso-scale numerical model that could consider the heterogeneities of concrete and concrete-steel tube interactions in order to evaluate the size effect in concrete-filled steel tubular columns. Dai et al. [17] assessed strength of concrete-filled stainless steel tube stub columns through experimental and numerical programs. Nevertheless, the compressive behaviour of concrete-filled steel tube stub (CFSTS) columns with different cross-sectional shapes of circular, square, and rectangular is studied in this paper.

The current paper is concerned with the compressive behaviour of circular, square, and rectangular CFSTS columns. As the accuracy of the finite element modelling is established using ABAQUS, the method is followed for the developed CFSTS columns. Load eccentricity, cross-sectional shape, and steel tube thickness are considered as the parameters in the analyses of the columns. Effects of these parameters on the ultimate load-carrying capacity, energy absorption capacity, and stiffness of the columns are discussed. Failure modes of the columns are evaluated too.

\section{Materials and Methods}

Materials employed in the studied CFSTS columns consist of the perimeter steel tube filled with concrete. This section deals with the experimental test and numerical modelling of the CFSTS columns. An experimental test done on a CFSTS column [18] was modelled by ABAQUS in order to validate the nonlinear three-dimensional finite element modelling of the CFSTS columns in this research.

\subsection{Experimental Test of CFSTS Column}

The CFSTS column was tested under concentric load applied on its entire section. The main geometric characteristics of the tested column were diameter $(D)$, thickness of steel tube $(t)$, and length/diameter ratio $(L / D)$ respectively as $114.3 \mathrm{~mm}, 3.35 \mathrm{~mm}$, and 3 . The concrete compressive strength was $32.7 \mathrm{MPa}$ while the yield stress of the steel tube was $287.33 \mathrm{MPa}$. The test was conducted utilising an Instron 8506 servo hydraulic actuator with electronic displacement control.

\subsection{Numerical Modelling and Nonlinear Analysis of CFSTS Column}

The tested CFSTS column was modelled using ABAQUS as a popular finite element software. ABAQUS has a wide range of applications in solving physical problems and phenomena such as solid mechanics, fire and heat transfer, mass infiltration, thermal analysis of electrical components, acoustics, soil mechanics, and piezoelectrics. It can investigate and analyse results very close to reality by carefully examining them.

\subsubsection{Validation of Modelling}

The method of the modelling validation was such that the experimentally tested column was completely modelled so that the modelling result could be accomplished very close to the test result, accordingly, the modelling was validated.

All the considered features in the tested CFSTS column were also adopted in the modelling. Modelling the steel and concrete materials of the columns was performed as its fundamental part [19]. A concrete damage plasticity model was employed in modelling the concrete material [20]. Since concrete was greatly influenced by the confinement effect of the steel tube, its behaviour was different from other common models. The ratio of the second stress invariants on the tensile and compressive meridians $\left(K_{c}\right)$ was selected as 0.667 [21, 22]. The viscosity parameter utilised for better convergence was 0.0001 . A bilinear steel material model which had progressive hardening behaviour and softening effects was employed for modelling the steel material $[23,24]$. The Poisson's ratios of the steel tube and concrete were also taken as 0.3 and 0.2 , respectively.

The concrete infill and steel tube were respectively modelled by the use of the solid element C3D8R and the shell element S4R. The constraint called Embedded Region was utilised to model the contact surface between the concrete core and perimeter steel tube. The used friction coefficient $(\mu)$ for the contact was $0.3[21,22]$. The load 
was applied by the displacement method. The optimised mesh size of $15 \mathrm{~mm}$ was taken into account for the column which was obtained from a conducted convergence study on the mesh size of the model. This mesh size showed to be able to conclude accurate results. Modelled CFSTS column is presented in Figure 1.

The modelled CFSTS column was nonlinearly analysed and the load-axial strain curve was plotted from the analysis result. The finite element analysis result was compared with the experimental test result, as illustrated in Figure 2. It is noteworthy that as the differences between the resulted values and behaviours of the test and software model were lower in the validation process of the modelling, the analyses results of the developed models would be more accurate and reliable. Hence, it is observed from the figure that the curves agreed very well with each other with respect to their ultimate loads and behaviours. This good agreement obviously revealed the accuracy of the modelling and the modelling method was validated. Accordingly, the proposed modelling method could lead to exact results which was adopted for modelling the developed CFSTS columns.

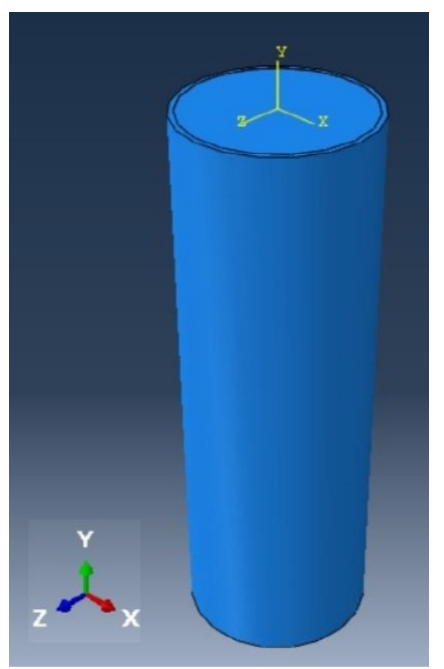

Figure 1. Modelled CFSTS column

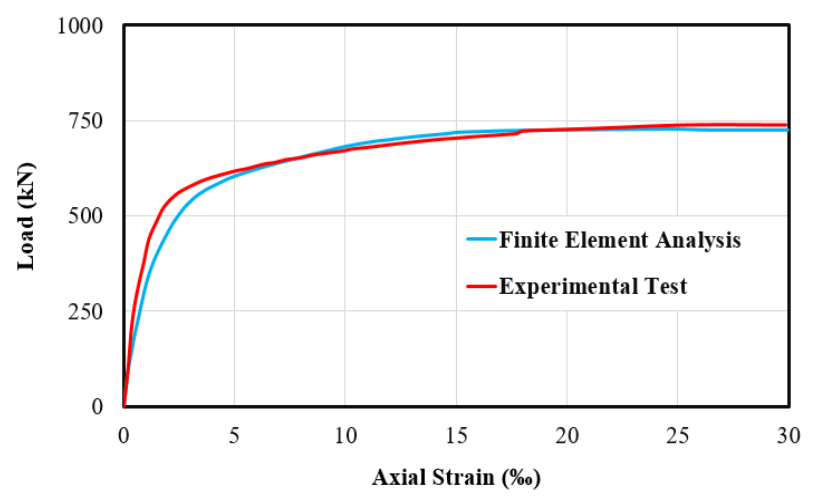

Figure 2. Comparison of finite element analysis result with experimental test result of CFSTS column

\subsubsection{Development of CFSTS Models}

With regard to the accomplished validated modelling method of the column, the CFSTS columns with the same height and materials characteristics were developed accounting for different parameters as load eccentricities (25 $\mathrm{mm}$ and $50 \mathrm{~mm}$ ), other cross-sectional shapes (square and rectangular), and other steel tube thicknesses $(2 \mathrm{~mm}$ and $5 \mathrm{~mm}$ ). The columns were analysed and their results were then achieved. In the columns labels of section 3, the first two letters respectively represent the cross-sectional shape and column as CC (Circular Column), SC (Square Column), and RC (Rectangular Column). In addition, the numbers following $e$ (eccentricity) and $t$ (thickness) respectively refer to the values of the load eccentricity and steel tube thickness in $\mathrm{mm}$.

\section{Results and Discussions}

The obtained results from the analyses of the developed CFSTS columns are presented herein. Also, effects of the considered parameters as load eccentricity, cross-sectional shape, and steel tube thickness on the ultimate load-carrying capacity, energy absorption capacity, and stiffness of the columns are discussed.

\subsection{Effects of Load Eccentricity on Ultimate Load-Carrying Capacity, Energy Absorption Capacity, and Stiffness of CFSTS Columns}

The analysed CFSTS column under the concentric load was also analysed under eccentric loads. Different eccentricities of $25 \mathrm{~mm}$ and $50 \mathrm{~mm}$ were applied for the load. Figure 3 demonstrates a typical modelled CFSTS column showing the load eccentricity and support conditions.

The load-axial strain curves were achieved for the columns (Figure 4). According to the figure, the ultimate load-carrying capacity of the CFSTS column with the load eccentricity of $0 \mathrm{~mm}$ (CC-e0-t3.35) was $729 \mathrm{kN}$ which was decreased to $630 \mathrm{kN}$ and $495 \mathrm{kN}$ respectively by increasing the eccentricity to $25 \mathrm{~mm}$ in CC-e25-t3.35 and $50 \mathrm{~mm}$ in CC-e50-t3.35. This issue indicates that increasing the load eccentricity from $0 \mathrm{~mm}$ to $50 \mathrm{~mm}$ reduced the ultimate load-carrying capacity of the column for $32.1 \%$. Because the eccentricity of the load brought the secondary moment with itself which had a negative effect on the capacity of the columns and reduced their ultimate load-carrying capacity.

The energy absorption capacities of the columns are compared in Figure 5. As the load eccentricity was increased from $0 \mathrm{~mm}$ to $25 \mathrm{~mm}$ and $50 \mathrm{~mm}$, the energy absorption capacity was decreased from $7483 \mathrm{kN} . \mathrm{mm}$ to 7017 kN.mm and 5334 kN.mm, respectively. Because with increasing the load eccentricity, stress concentration occurred on small parts of the steel tube which caused it to 
fail sooner and it prevented the application of the full capacity of the steel tube to absorb the energy. On the other hand, the concrete core inside the steel tube also suffered from internal shear cracks and partial failure due to the eccentric loads. Over time, these cracks were developed and caused more stress on the steel tube which finally led to lower energy absorption capacity of the columns.

The columns with larger load eccentricities resulted in lower stiffness (Figure 6). The initial stiffness of the column was reduced for $41.1 \%$ as the load eccentricity was enhanced from $0 \mathrm{~mm}$ in $\mathrm{CC}$-e 0 -t 3.35 to $50 \mathrm{~mm}$ in CC-e50-t3.35. In the column with $0 \mathrm{~mm}$ eccentricity, all or a large part of the capacity of the column was successfully utilised for the stiffness, but in the columns with larger eccentricities, smaller part of the capacity of the column was employed because of the existence of non-uniform stresses in the concrete core and steel tube which created and developed cracks in the cross-section.

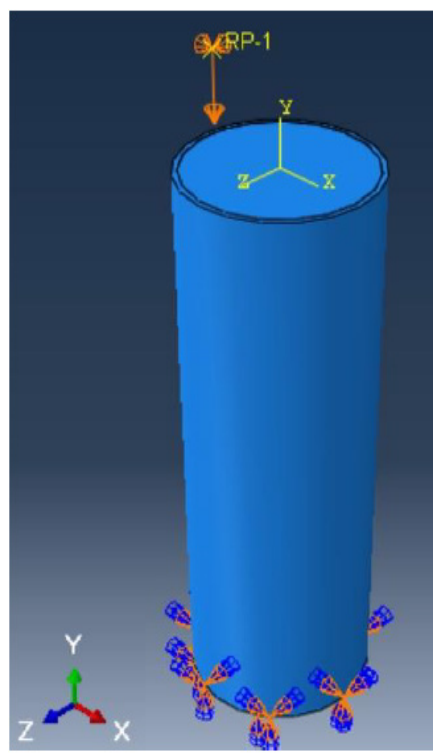

Figure 3. Typical modelled CFSTS column showing load eccentricity and support conditions

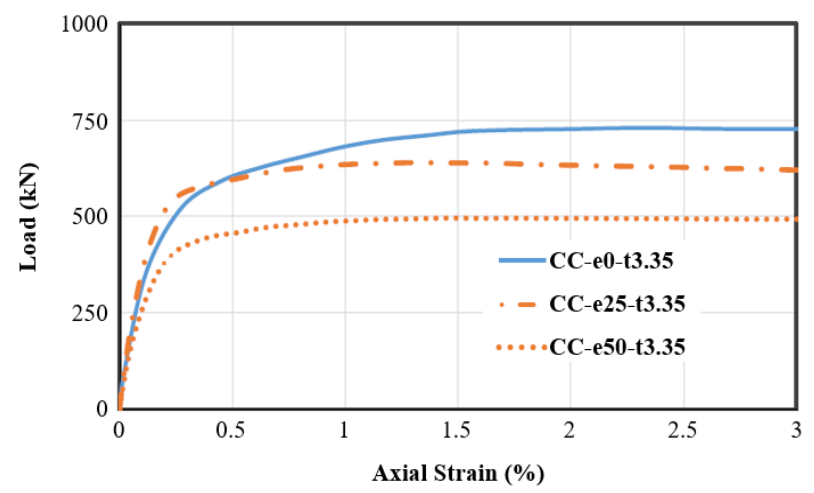

Figure 4. Effect of load eccentricity on ultimate load-carrying capacity of CFSTS columns

\subsubsection{Failure Modes of Circular CFSTS Columns with Different Load Eccentricities}

Failure modes of the circular CFSTS columns are illustrated in Figure 7. As it can be seen from the figure, less buckling occurred in the column with $0 \mathrm{~mm}$ load eccentricity $(e=0 \mathrm{~mm})$ than in the columns with the eccentricities of $25 \mathrm{~mm}$ and $50 \mathrm{~mm}$. Also, the failure and stress distribution were in a more uniform way along the entire length of the column with $e=0 \mathrm{~mm}$. However, buckling occurred about the top of the columns with the load eccentricities of $25 \mathrm{~mm}$ and $50 \mathrm{~mm}$ which revealed the concentration of stresses about the top of these columns.

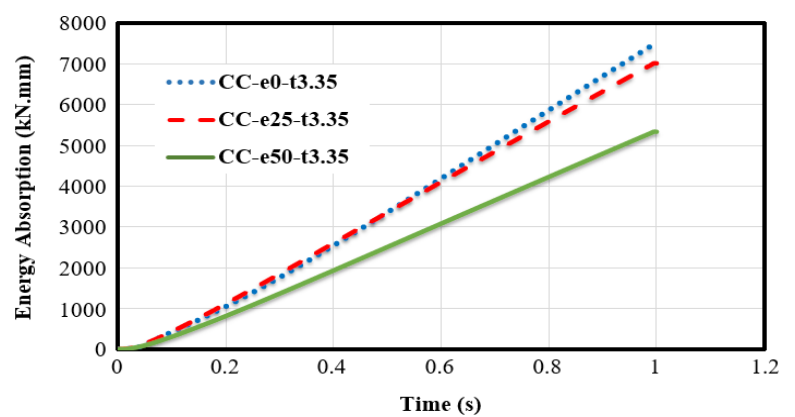

Figure 5. Effect of load eccentricity on energy absorption capacity of CFSTS columns

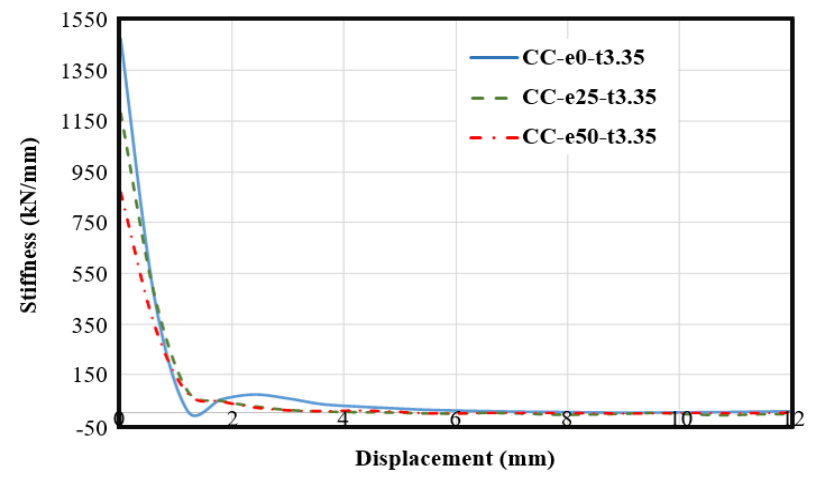

Figure 6. Effect of load eccentricity on stiffness of CFSTS columns

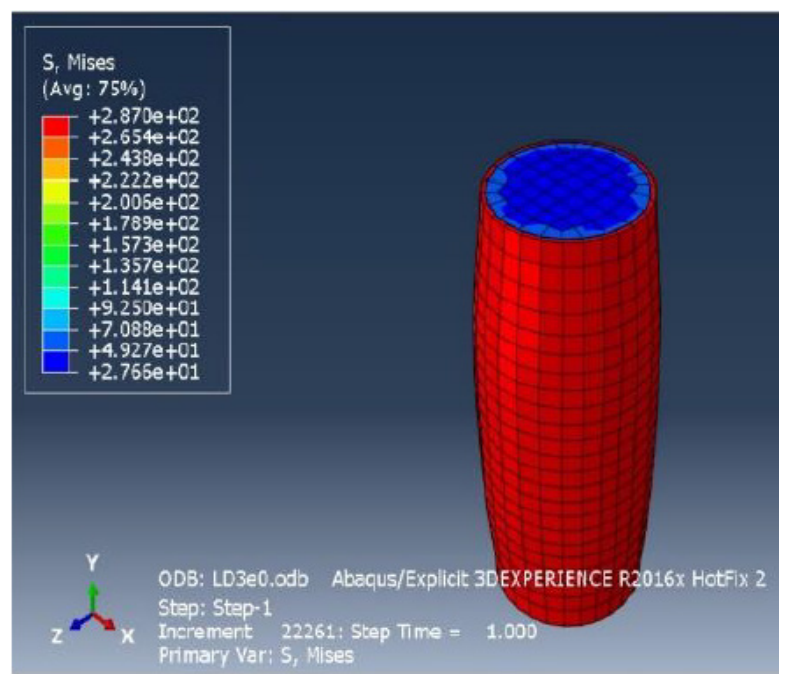

(a)

Figure 7. Failure modes of CFSTS columns: (a) CC-e0-t3.35, (b) CC-e25-t3.35, (c) CC-e50-t3.35 


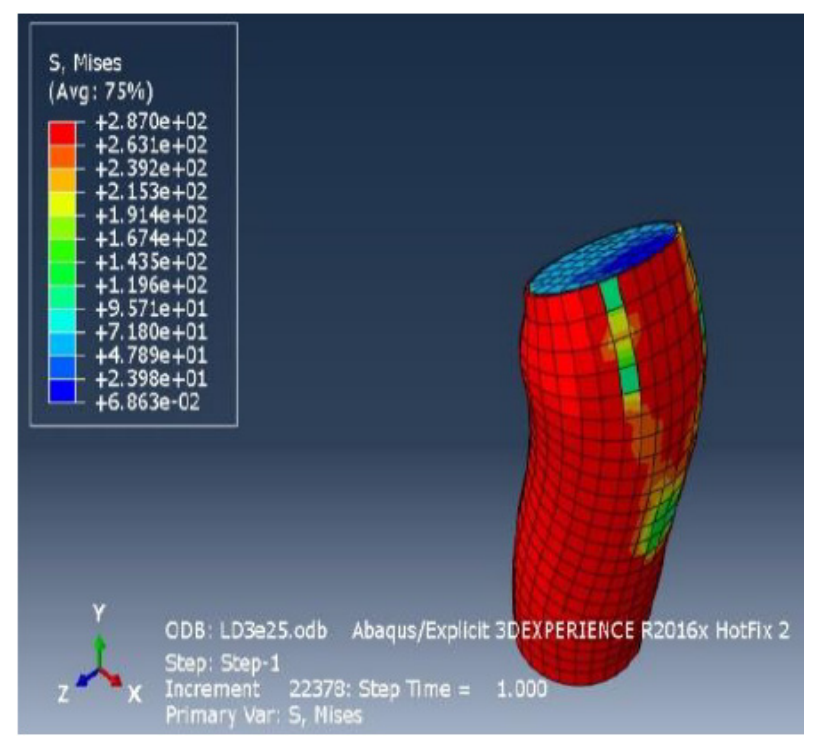

(b)

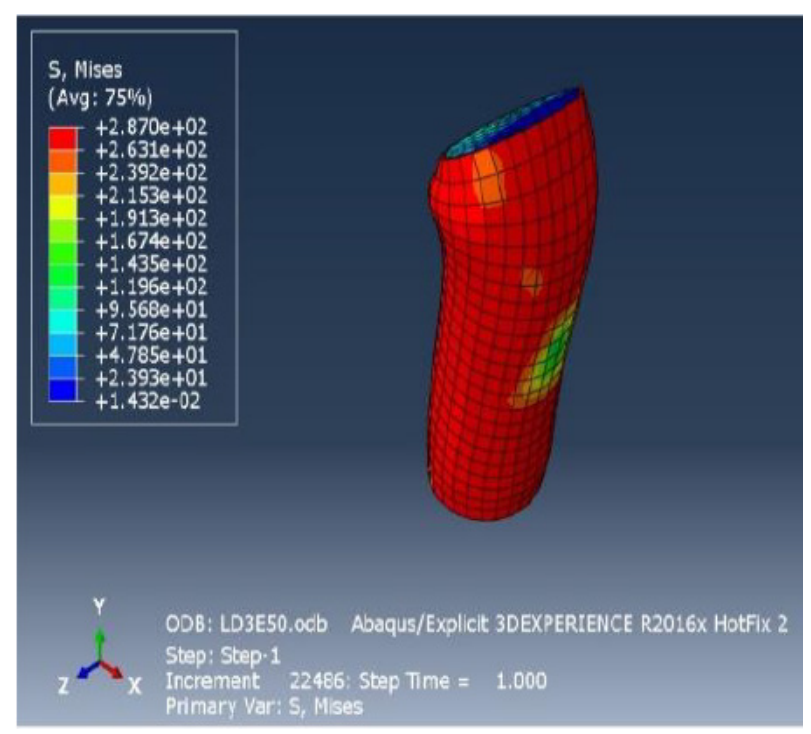

(c)

Figure 7. Continued

\subsection{Effects of Cross-Sectional Shape on Ultimate Load-Carrying Capacity, Energy Absorption Capacity, and Stiffness of CFSTS Columns}

In addition to the circular cross-sectional shape for the column, other shapes of the square and rectangular were considered for the columns. These columns were modelled and analysed. All the specifications of the circular column were taken into account for the square and rectangular columns. Also, the same cross-sectional area and length of the circular column were adopted here so that the concrete volume and steel tube area were identical for all the columns.

As it is demonstrated in Figure 8, the circular column had higher ultimate load-carrying capacity than the rectangular and square columns which were respectively as
$729 \mathrm{kN}, 677 \mathrm{kN}$, and $670 \mathrm{kN}$. It was uncovered that when the cross-sectional shape changed from square to circular, the ultimate load-carrying capacity of the column was improved for $8.8 \%$. However, the ultimate load-carrying capacities of the square and rectangular columns had a slight difference. Thus, the hierarchy of different cross-sectional shapes of the columns with respect to the ultimate load-carrying capacity was the circular, rectangular, and square shapes. The rigidity of the plane portions of the steel tube in the rectangular and square sections was not sufficient to withstand the internal pressures owing to the expansion of the concrete core. Therefore, only concrete in the centre and corners of the cross-section was effectively confined, however, the confinement effect of the steel tube in the circular column was identical throughout the perimeter of the tube. This point finally resulted in the failure of the rectangular and square columns in lower ultimate loads than that of the circular column.

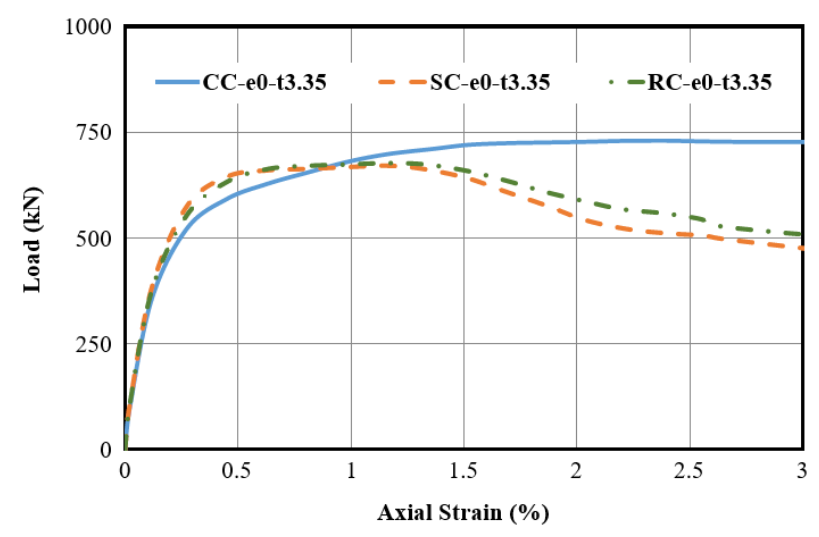

Figure 8. Effect of cross-sectional shape on ultimate load-carrying capacity of CFSTS columns

It is clear that the slope of the graphs in Figure 9 as well as their behaviour were almost similar for the energy absorption capacity of the columns, but the maximum force absorbed by the circular column was $17.3 \%$ and $12.2 \%$ higher than those of the square and rectangular columns, respectively. Because the distribution of tri-axial and loop stresses created by the steel tube was carried out more appropriately and uniformly in the circular column than the square and rectangular columns due to not having plane portions and angles. Also, the friction between the concrete core and steel tube in the circular cross-section was more which caused the delay of the steel tube failure and its proper energy absorption. The same hierarchy of the cross-sectional shapes of the columns from the ultimate load-carrying capacity view was also witnessed from the energy absorption capacity viewpoint as the circular, rectangular, and square shapes.

The values of the initial stiffness of the circular, square, and rectangular columns were respectively as $1477 \mathrm{kN} / \mathrm{mm}$, $1530 \mathrm{kN} / \mathrm{mm}$, and $1583 \mathrm{kN} / \mathrm{mm}$ (Figure 10). According to the obtained results, it is obvious that the initial stiffness of the rectangular column was higher than the other two 
columns, however, the overall stiffness of the rectangular and square columns was not properly distributed throughout their sections based on the behavioural form of their curves. Owing to more uniform distribution of the stiffness in the whole section of the circular column than the rectangular and square columns, the circular section was preferred to others.

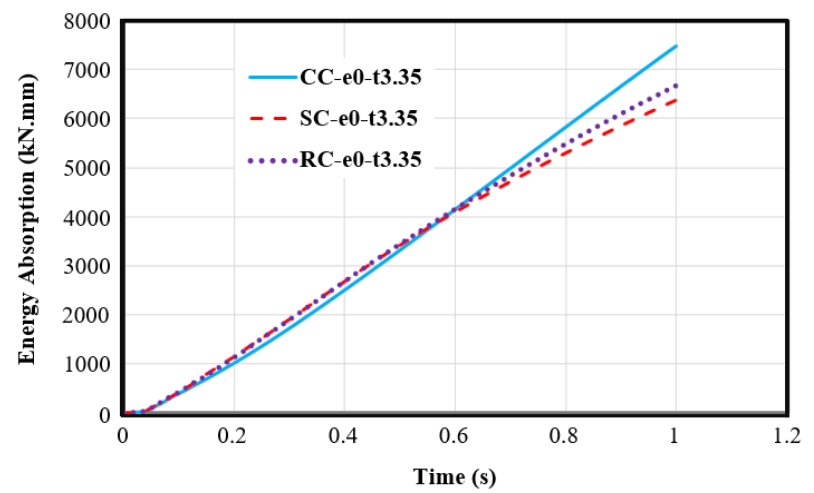

Figure 9. Effect of cross-sectional shape on energy absorption capacity of CFSTS columns

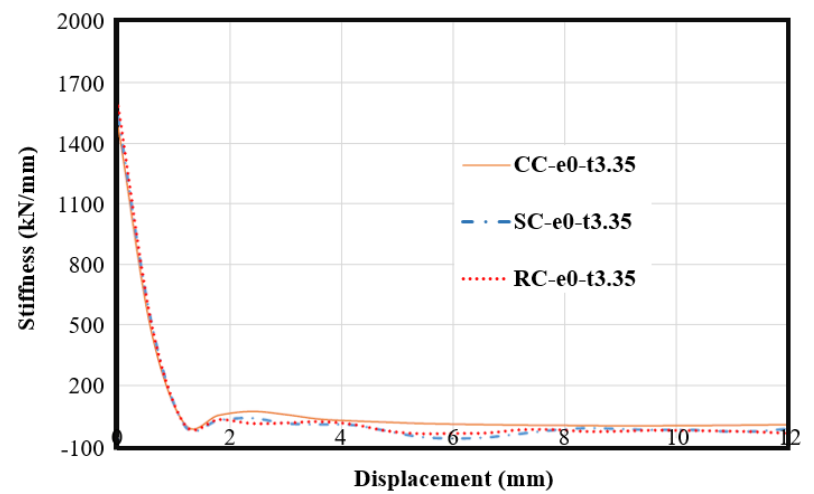

Figure 10. Effect of cross-sectional shape on stiffness of CFSTS columns

\subsubsection{Failure Modes of CFSTS Columns with Different Cross-Sectional Shapes}

Aside from the failure modes of the circular columns which were displayed and discussed in section 3.1.1, Figure 11 indicates the failure modes of the square and rectangular columns. It can be perceived from the figure that the failure modes of the columns were characterised by their buckling. High tensile stresses occurred on one side of the columns and compressive stresses on the other side.

\subsection{Effects of Thickness of Steel Tube on Ultimate Load-Carrying Capacity, Energy Absorption Capacity, and Stiffness of CFSTS Columns}

Since the confinement effect of the steel tube on the concrete core is an important influencing factor on the performance of the CFSTS columns, effects of the steel tube thickness are assessed here. The increase of the steel tube thickness from $2 \mathrm{~mm}$ to $5 \mathrm{~mm}$ resulted in the improvement of the ultimate load-carrying capacity of the columns for $46.4 \%$ (Figure 12). Because thicker steel tube, lower diameter to thickness ratio $(D / t)$, made the steel tube have better confinement effect on the concrete core and delayed the failure of the columns that finally led to their larger ultimate load-carrying capacity.

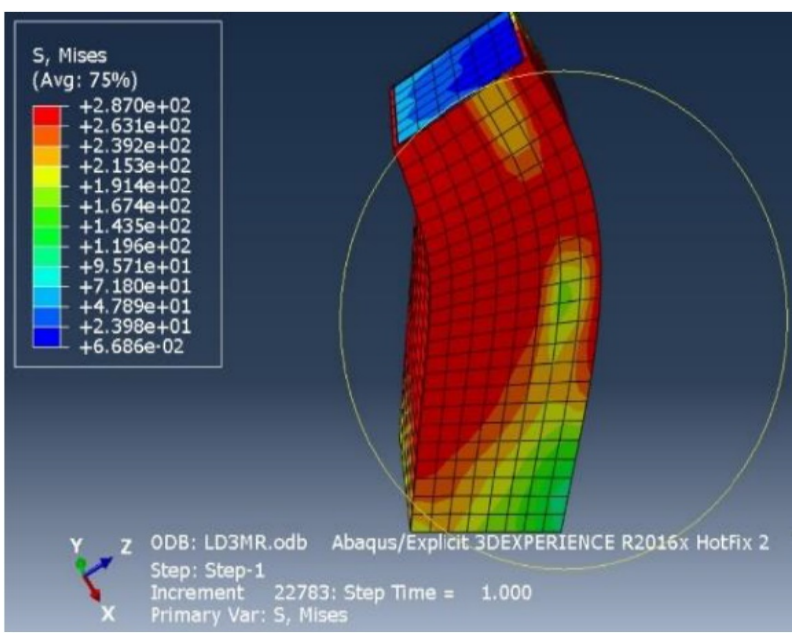

(a)

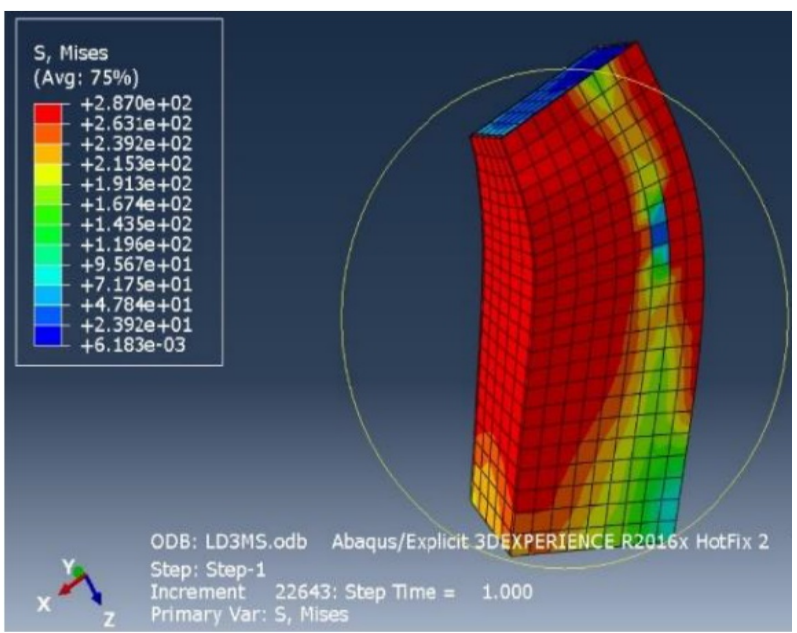

(b)

Figure 11. Failure modes of CFSTS columns: (a) SC-e0-t3.35, (b) RC-e0-t3.35

The energy absorption capacity of CC-e 0 - $\mathrm{t} 2$ was 5975 kN.mm which was enhanced to 9224 kN.mm (CC-e0-t5) by the increase of the steel tube thickness from $2 \mathrm{~mm}$ to 5 $\mathrm{mm}$, an enhancement of $54.4 \%$ (Figure 13). Since the main role in the energy absorption of the CFSTS columns is played by the steel tube, increasing the steel tube thickness improved its mentioned role and increased the energy absorption capacity of the columns.

The enhancement of the steel tube thickness enhanced the stiffness of the columns (Figure 14) which once more was owing to its positive effect on increasing the confinement of the steel tube on the concrete infill that 
helped prevent the occurrence of cracks in concrete and early local buckling of the columns.

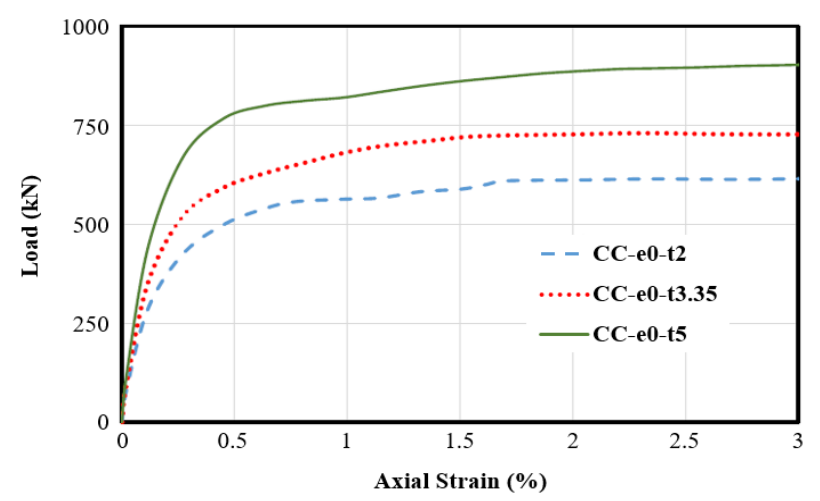

Figure 12. Effect of steel tube thickness on ultimate load-carrying capacity of CFSTS columns

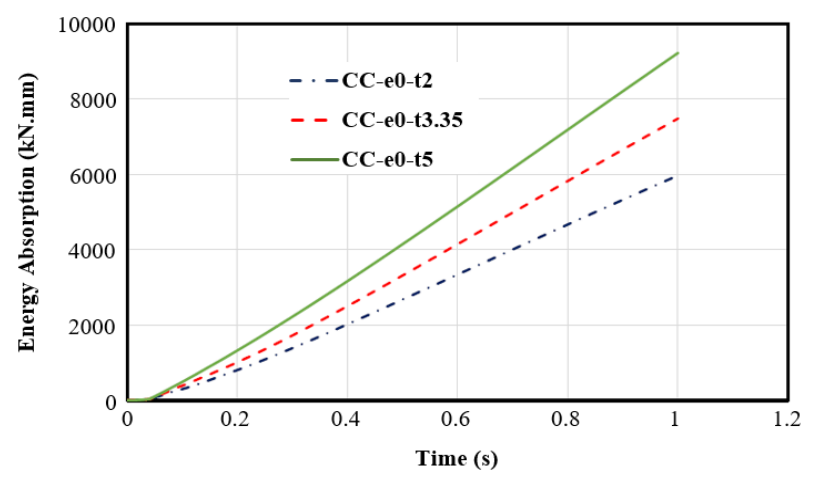

Figure 13. Effect of steel tube thickness on energy absorption capacity of CFSTS columns

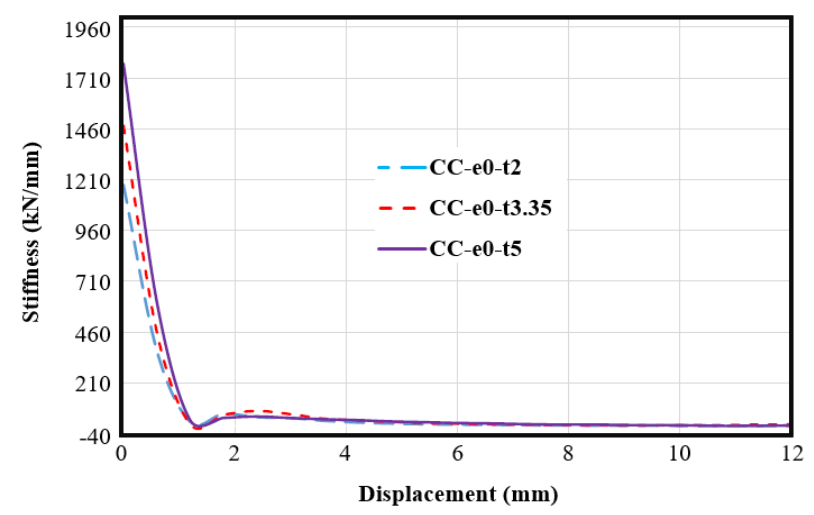

Figure 14. Effect of steel tube thickness on stiffness of CFSTS columns

\section{Conclusions}

This paper focused on the compressive behaviour of circular, square, and rectangular CFSTS columns. The columns were analysed using ABAQUS. Modelling verification of the columns was established by comparison of the modelling and test results. Developed columns were analysed considering the parameters of load eccentricity, cross-sectional shape, and steel tube thickness. Effects of these parameters on the ultimate load-carrying capacity, energy absorption capacity, and stiffness of the columns were investigated. As a conclusion, the ultimate load-carrying capacity, energy absorption capacity, and stiffness were reduced by increasing the load eccentricity. With regard to the ultimate load-carrying capacity and energy absorption capacity, the hierarchy of the cross-sectional shapes of the columns was the circular, rectangular, and square shapes. Generally, the circular columns were superior to the rectangular and square columns. Larger ultimate load-carrying capacity, energy absorption capacity, and stiffness were achieved by enhancing the steel tube thickness. Buckling and large stress concentration were mainly observed in the failure modes of the columns. Future scope of this research is the evaluation of concrete-filled steel tube slender columns considering various variables influencing their structural behaviour.

\section{REFERENCES}

[1] B. Uy, S. B. Patil. Concrete-filled high strength steel box columns for tall buildings: behaviour and design, Structural Design of Tall Buildings, Vol. 5, 75-94, 1996.

[2] D. Liu, W. M. Gho, J. Yuan. Ultimate capacity of high-strength rectangular concrete-filled steel hollow section stub columns, Journal of Constructional Steel Research, Vol. 59, 1499-1515, 2003.

[3] L. H. Han, G. H. Yao, X. L. Zhao. Tests and calculations for hollow structural steel (HSS) stub columns filled with self-consolidating concrete (SCC), Journal of Constructional Steel Research, Vol. 61, 1241-1269, 2005.

[4] Z. Tao, L. H. Han, D. Y. Wang. Experimental behaviour of concrete-filled stiffened thin-walled steel tubular columns, Thin-Walled Structures, Vol. 45, 517-527, 2007.

[5] L. H. Han, W. Liu, Y. F. Yang. Behaviour of concrete-filled steel tubular stub columns subjected to axially local compression, Journal of Constructional Steel Research, Vol. 64, 377-387, 2008.

[6] J. Y. R. Liew, D. X. Xiong. Effect of preload on the axial capacity of concrete-filled composite columns, Journal of Constructional Steel Research, Vol. 65, 709-722, 2009.

[7] W. L. A. Oliveira, S. De Nardin, A. L. H. C. El Debs, M. K. El Debs. Evaluation of passive confinement in CFT columns, Journal of Constructional Steel Research, Vol. 66, 487-495, 2010.

[8] B. Uy, Z. Tao, L. H. Han. Behaviour of short and slender concrete-filled stainless steel tubular columns, Journal of Constructional Steel Research, Vol. 67, 360-378, 2011.

[9] A. Bahrami, W. H. Wan Badaruzzaman, S. A. Osman. Behaviour of stiffened concrete-filled steel composite (CFSC) stub columns, Latin American Journal of Solids and Structures, Vol. 10, No. 2, 409-439, 2013.

[10] A. Bahrami, W. H. Wan Badaruzzaman, S. A. Osman. Investigation of concrete-filled steel composite (CFSC) stub 
columns with bar stiffeners, Journal of Civil Engineering and Management, Vol. 19, No. 3, 433-446, 2013.

[11] A. Bahrami, W. H. Wan Badaruzzaman, S. A. Osman. Numerical study of concrete-filled steel composite (CFSC) stub columns with steel stiffeners, Latin American Journal of Solids and Structures, Vol. 11, No. 4, 683-703, 2014.

[12] D. Faxing, F. Lei, Y. Zhiwu, L. Gang. Mechanical performances of concrete-filled steel tubular stub columns with round ends under axial loading, Thin-Walled Structures, Vol. 97, 22-34, 2015.

[13] L. Zhu, L. Ma, Y. Bai, S. Li, Q. Song, Y. Wei, L. Zhang, Z. Zhang, X. Sha. Large diameter concrete-filled high strength steel tubular stub columns under compression, Thin-Walled Structures, Vol. 108, 12-19, 2016.

[14] A. Zhu, X. Zhang, H. Zhua, J. Zhu, Y. Lu. Experimental study of concrete filled cold-formed steel tubular stub columns, Journal of Constructional Steel Research, Vol. 134, 17-27, 2017.

[15] G. Li, B. Chen, Z. Yang, Y. Feng. Experimental and numerical behaviour of eccentrically loaded high strength concrete filled high strength square steel tube stub columns, Thin-Walled Structures, Vol. 127, 483-499, 2018.

[16] L. Jin, L. Fan, P. Li, X. Du. Size effect of axial-loaded concrete-filled steel tubular columns with different confinement coefficients, Engineering Structures, Vol. 198, 109503, 2019.

[17] P. Dai, L. Yang, J. Wang, Y. Zhou. Compressive strength of concrete-filled stainless steel tube stub columns, Engineering Structures, Vol. 205, 110106, 2020.
[18] W. L. A. Oliveira, S. De Nardin, A. L. H. C. El Debs, M. K. El Debs. Influence of concrete strength and length/diameter on the axial capacity of CFT columns, Journal of Constructional Steel Research, Vol. 65, 2103-2110, 2009.

[19] A. Bahrami, W. H. Wan Badaruzzaman, S. A. Osman. Performance of axially loaded tapered concrete-filled steel composite slender columns, Journal of Civil Engineering and Management, Vol. 19, No. 5, 705-717, 2013.

[20] A. Bahrami, M. Yavari. Hysteretic assessment of steel-concrete composite shear walls, International Journal of Recent Technology and Engineering, Vol. 8, No. 2, 5640-5645, 2019.

[21] W. Qiu, F. McCann, A. Espinos, M. L. Romero, L. Gardner. Numerical analysis and design of slender concrete-filled elliptical hollow section columns and beam-columns, Engineering Structures, Vol. 131, 90-100, 2017.

[22] C. Wang, Z. Yun, J. Kang, Y. Zhou, M. Chen, Y. Wu. Behavior of an innovative square composite column made of four steel tubes at the corners and corrugated steel batten plates on all sides, Advances in Civil Engineering, Vol. 2019, 2971962, 2019.

[23] A. Bahrami, W. H. Wan Badaruzzaman, S. A. Osman. Nonlinear analysis of concrete-filled steel composite columns subjected to axial loading, Structural Engineering and Mechanics, Vol. 39, No. 3, 383-398, 2011.

[24] A. Bahrami, S. Matinrad. Response of steel beam-to-column bolted connections to blast loading, International Journal of Recent Technology and Engineering, Vol. 8, No. 3, 3639-3648, 2019. 